Presented at the I\&EC Special Symposium

American Chemical Society

Atlanta, GA, September 19-21, 1994

\title{
METHOD OF CHARACTERIZING VOC CONCENTRATION IN VENTED WASTE DRUMS WITH MULTIPLE LAYERS OF CONFINEMENT USING LIMTTED SAMPLING DATA
}

\author{
Kevin J. Liekhus, M. E. Vaughn, B. A. Jensen, M. J. Connolly \\ Idaho National Engineering Laboratory, Idaho Falls, ID
}

\begin{abstract}
Characterization of transuranic waste destined for the Waste Isolation Pilot Plant currently requires detailed characterization of the volatile organic compound (VOC) concentration in the void volume headspaces (drum headspace, the large polymer bag headspace, and the innermost layers of confinement headspace) of the waste drums. A test program is underway at the Idaho National Engineering Laboratory (INEL) to determine if the drum headspace VOC concentration is representative of the concentration in the entire drum void space and demonstrate that the VOC concentration in the innermost layer of confinement can be estimated using a model incorporating diffusion and permeation transport principles and limited waste drum sampling data. A comparison of model predictions of VOC concentration in the innermost layer of confinement with actual measurement from transuranic waste drums demonstrate that this method may be useful in characterizing VOC concentration in a vented waste drum.
\end{abstract}

\section{INTRODUCTION}

Currently, characterization of transuranic (TRU) waste destined for the Waste Isolation Pilot Plant (WIPP) requires detailed characterization of the volatile organic compound (VOC) concentration in the void volume headspaces (drum headspace, the large polymer bag headspace, and the innermost layers of confinement headspace) of the waste drums. The objectives of the extensive sampling are to obtain a representative sample from each layer of confinement to identify volatile and gaseous constituents, verify process knowledge of the drum contents, and demonstrate compliance with regulatory requirements. The Department of Energy (DOE) must demonstrate to the Environmental Protection Agency (EPA) that a drum headspace sample is representative of the VOCs within the entire void space of the waste container in order to demonstrate compliance in the future when drums could be directly emplaced in the WIPP. The WIPP conditional no-migration determination (NMD) specifies that the EPA expects that all layers of confinement in a container will have to be sampled until DOE can demonstrate, based on data collected, that sampling of all layers is either unnecessary or can be safely reduced. ${ }^{1}$

The regulatory requirements specify maximum acceptable concentrations for certain VOCs in all layers of confinement. The WIPP conditional NMD requirements specify the maximum allowable concentrations of hazardous constituents. Transportation safety issues requires that no layer of confinement contains a mixture of gases and VOCs that could become flammable when mixed with air. ${ }^{2}$ An important issue is whether gas samples must be collected from all layers of confinement to obtain representative headspace samples from a waste drum to meet these requirements. A systematic means of describing the VOC concentrations within the innermost layer of confinement, based on the drum headspace concentration, would suggest that the drum headspace sample is representative. 


\section{VOC TRANSPORT MODEL}

A model was developed to estimate the maximum VOC concentration in the innermost layer of confinement within a vented waste drum based on knowledge of the drum headspace VOC concentration. Model parameters include permeable surface area of the bag, bag thickness, bag material, cross-sectional area of the opening in the liner lid, VOC permeability across the bag, VOC diffusivity in air, and VOC diffusion characteristic across the filter vent. All model parameters except the permeable surface area can be defined a priori from available process knowledge of the waste drum configuration. The waste drum configuration includes the type of filter vent in the drum lid, the dimensions of the opening the drum liner lid, and the type, number, and thickness of the bags. The model consists of a series of material balance equations describing steady-state VOC transport from each distinct void volume in the drum.

The primary mechanisms for steady-state gas transport across a polymer boundary are permeation across the polymer and diffusion across an opening in the boundary. The steady-state gas tran̈sport via permeation across a polymer film is defined as

$$
\begin{aligned}
& r=-\left[\frac{\phi \odot A_{p} P}{x_{p}}\right] c \Delta y_{p}=K_{p} \Delta y_{p} \\
& \text { where } \\
& \mathbf{r}=\text { VOC transport rate, } \mathrm{mol} \mathrm{s}^{-1} \\
& \phi \quad=\quad 76 \mathrm{~T} /(273.15 \mathrm{P}) \\
& \mathrm{T}=\text { temperature, } \mathrm{K} \\
& \mathrm{P} \quad=\text { pressure, } \mathrm{cm} \mathrm{Hg} \\
& \rho=\text { gas permeability coefficient, } \mathrm{cm}^{3}(\mathrm{STP}) \mathrm{cm} \mathrm{cm}^{-2}(\mathrm{~cm} \mathrm{Hg})^{-1} \mathrm{~s}^{-1} \\
& A_{p}=\text { polymer surface area across which VOC permeates, } \mathrm{cm}^{2} \\
& \mathrm{x}_{\mathrm{p}}=\text { polymer boundary thickness, } \mathrm{cm} \\
& \mathrm{c}=\text { total gas concentration }=\mathrm{P}(\mathrm{RT})^{-1}, \mathrm{~mol} \mathrm{~cm}^{-3} \\
& \mathrm{R}=6236.6 \mathrm{~cm}^{3}(\mathrm{~cm} \mathrm{Hg}) \mathrm{mol}^{-1} \mathrm{~K}^{-1} \\
& \Delta y_{p}=\text { gas mole fraction difference across polymer } \\
& \mathrm{K}_{\mathrm{p}}=\text { permeation characteristic, } 4.46 \times 10^{-5} \mathrm{PA}_{\mathrm{p}} \mathrm{P} \mathrm{x}_{\mathrm{p}}^{-1} \text {, mol s}
\end{aligned}
$$

The steady-state gas transport across an opening in polymer boundary layer via gas diffusion is defined as

$r=-\left[\frac{D A_{d}}{x_{d}}\right] c \Delta y_{p}=K_{d} \Delta y_{p}$

where

$\mathrm{D}=$ gas diffusivity in air, $\mathrm{cm}^{2} \mathrm{~s}^{-1}$

$\mathrm{A}_{\mathrm{d}}=$ cross-sectional area of opening across polymer boundary, $\mathrm{cm}^{2}$

$x_{d}=$ diffusional length across opening, $\mathrm{cm}$

$\mathrm{K}_{\mathrm{d}}=$ diffusion characteristic, $\mathrm{DA}_{\mathrm{d}} \mathrm{P}\left(\mathrm{RTx}_{\mathrm{d}}\right)^{-1}$, mol s${ }^{-1}$

Most other waste drums contain waste packaged in one or more layers of small polymer bags. These smaller bags were then placed inside a larger polymer bag. The polymer bag immediately surrounding the waste is the innermost layer of confinement and the headspace inside this layer of 


\section{DISCLAIMER}

Portions of this document may be illegible electronic image products. Images are produced from the best available original document. 
confinement is referred to as the first void volume. The headspaces in the large bag, drum liner, and " drum are the subsequent void volumes and are numbered accordingly. The VOC transport rate from the innermost layer of confinement is defined by the equation

$$
r=K_{p, 1}\left(y_{1}-y_{2}\right) \text {. }
$$

where

$$
\mathrm{K}_{\mathrm{p}, 1}=\text { permeation characteristic of boundary of first layer of confinement, mol } \mathrm{s}^{-1}
$$

The VOC transport across the large polymer bags containing the smaller bags is defined as

$$
r=K_{p, 2}\left(y_{2}-y_{3}\right) \text {. }
$$

The rate of VOC transport across the drum liner is defined as

$$
r=K_{d}\left(y_{3}-y_{4}\right) \text {. }
$$

The rate of VOC transport from the drum headspace across the filter vent is defined as

$$
r=D^{*}\left(y_{4}-y_{5}\right) \text {. }
$$

where

$$
\begin{aligned}
& D^{*}=\text { drum filter vent VOC diffusion characteristic } \\
& y_{\infty}=\text { VOC mole fraction outside waste drum }
\end{aligned}
$$

Equation (6) is used to define the steady-state VOC transport rate in the drum. The VOC concentrations in the other void volumes are estimated using Equations (3) through (5).

$$
\begin{aligned}
& y_{3}=y_{4}+\frac{r}{K_{d}} \\
& y_{2}=y_{3}+\frac{r}{K_{p, 2}} \\
& y_{1}=y_{2}+\frac{r}{K_{p, 1}} .
\end{aligned}
$$

The VOC permeability coefficients were measured across polyethylene at the INEL using a mixed-component chromatographic detection method. The diffusivities of most VOCs in air at a given temperature and pressure were identified in the literature. ${ }^{3}$ In the case where diffusivity data could not be identified, the VOC diffusivity in air was estimated using the transport equation ${ }^{4}$ 


$$
\begin{aligned}
D_{A B}= & 2.745 \times 10^{-4} \frac{T^{1.823}}{\Pi}\left[p_{c A} p_{c B}\right]^{1 / 3} \\
& {\left[T_{c A} T_{c B}\right]^{-1 / 2}\left[\frac{1}{M_{A}}+\frac{1}{M_{B}}\right]^{1 / 2} . }
\end{aligned}
$$

The VOC diffusion characteristics across different drum filter vents were measured in experiments performed at EG\&G Idaho. All model parameters, except the small bag surface area, were estimated from process knowledge prior to characterization of the waste drum contents. During actual waste characterization, the operator estimated the bag shape (rectangular, triangular, elliptical, or cylindrical) of each bag gas sampled and measured the characteristic dimensions of the bag. With these dimensions, the permeable surface area of each small bag was estimated. Using the smallest estimated surface area will result in the maximum calculated VOC concentration within the innermost layer of confinement.

The large bag surface area was estimated to be $2,565 \mathrm{~cm}^{2}$. Each large polyethylene bag was assumed to be $0.028 \mathrm{~cm}$ (11 mils) thick. Small polyethylene bags were assumed to be $0.013 \mathrm{~cm}$ ( 5 mils) thick and PVC bags were assumed to be $0.028 \mathrm{~cm}$ (11 mils) thick. The cross-sectional area of drum liner lid opening is $0.71 \mathrm{~cm}^{2}$. The diffusion length across the drum liner lid was estimated to be $1.2 \mathrm{~cm}$. The measured VOC diffusion characteristics across NFT-020 drum filter vents ranged from $2 \times 10^{-7}$ to $6 \times 10^{-7} \mathrm{~mol} \mathrm{~s}^{-1}$. The waste drums were maintained at ambient room temperature and pressure. When necessary, a temperature of $25^{\circ} \mathrm{C}$ and a pressure of $62.5 \mathrm{~cm} \mathrm{Hg}$ were used in model calculations.

The following assumptions were made in order to estimate the relationship between the VOC concentration measured in the drum headspace and the VOC concentrations in the other void volumes:

1. An equilibrium exists between the VOC-contaminated waste and the vapor phase in the innermost layer of confinement.

2. The VOC transport rates across all layers of confinement are equal and at steady state.

3. The primary mechanisms for VOC transport are permeation across the polymer bags and diffusion across the drum liner and drum filter vent.

4. A layer of confinement defined by multiple layers of polymer bags is considered a single polymer bag with a bag thickness equal to the sum of the bag thicknesses of the individual bags and a surface area equal to that of the outermost bag.

5. The VOC concentration throughout each void volume is uniform and is zero outside the waste drum.

6. All VOC properties and other model parameters remain constant. 


\section{EXPERIMENTAL}

Gas sampling and visual characterization of stored contact-handled transuranic waste was performed in the Argonne National Laboratory-West (ANL-W) Hot Fuel Examination Facility Waste Characterization Chamber (WCC). The WCC gas sampling system is a semi-automated process. Operators are responsible for installing a passivated SUMMA canister on the sample manifold and inserting the sample needle in the drum or bag headspace being sampled. The operator activates the computer-controlled process which opens and automatically closes the sample line upon sample collection. Additional tasks automatically performed during the gas sampling sequence include system cleaning with separate helium and air gas streams, validation of system cleanliness using a flame ionization detector, and a leak test of the sampling manifold. If detectable levels of VOCs are found, the cleaning sequence is repeated. The complete gas sampling sequence takes about 20 minutes.

A drum headspace sample was collected by inserting the sample needle through the NFT-020 drum filter vent in the drum lid. After gas sample collection, the drum and drum liner lids were removed. A headspace sample was collected from the innermost layer of the large polymer bags inside the drum liner. The top of each large polymer liner bag was then removed to allow the removal of smaller polymer bags. A gas sample from each separate bag was collected from the innermost layer of confinement that was not breached and contained at least $100 \mathrm{~mL}$ of void volume as decided by the operator. An effort was made to conduct the sampling of the drum headspace, the drum liner bag headspace, and the innermost layer of confinement of all small bags in one working day. In some cases, the drum and drum liner bag headspaces were sampled in one day and all small bags were sampled within the next 24 hours. In this case, the drum liner bags were not opened until the second day. Visual characterization consisted of video and audio taping of the gas sampling activities; estimating the bag material and wall thickness; identifying the shape of the bag; measuring the linear dimensions of each bag; and describing the waste contained in the bags.

\section{RESULTS}

Model estimates of the VOC concentration in the innermost layer of confinement were calculated assuming different values for the permeable surface area of the small bags. Calculations were initially performed assuming the smallest estimated surface area as determined from direct examination of the small bags. The minimum surface area range between 800 and $6,500 \mathrm{~cm}^{2}$. Comparison of estimated and maximum VOC concentrations for TCA and toluene within the innermost layer of confinement are shown in Figures 1 and 2. For most drums, the concentration ranges for TCA was from $100 \mathrm{ppm}$ to 1,000 and for toluene was from 10 to $100 \mathrm{ppm}$. Model estimates of TCA and toluene assuming a permeable surface area of $500 \mathrm{~cm}^{2}$ are shown in Figures 3 and 4 , respectively.

\section{DISCUSSION}

A majority of model results were equal to or greater than actual maximum VOC concentration in the innermost layer of confinement. There were exceptions where model predictions were significantly less than measured values. Errors in the measured VOC concentration will result in either the entry of incorrect input into model equations or inaccurate concentrations associated with the innermost layer of confinement.

All model parameters except the small bag surface area, could be estimated from process knowledge prior to characterization of the waste drum contents. The smallest estimated surface area of a bag from which a reasonable gas sample was collected was used as the basis for defining the 
model parameter. The bag with the smallest estimated area did not necessarily contain the highest VOC concentration. Waste characterization can identify the range of small bag surface area expected inside waste drums containing different waste types. The use of a bag surface area of $500 \mathrm{~cm}^{2}$ resulted in more conservative estimates of VOC concentrations in the innermost layer of confinement and eliminated the need to determine small bag surface area through direct examination of the waste.

\section{CONCLUSIONS}

The objective of this study was to determine if the drum headspace VOC concentration is representative of the concentration in the entire drum void space and demonstrate that the VOC concentration in the void space of each layer of confinement can be estimated using a model incorporating diffusion and permeation transport principles and limited waste drum sampling data. For the majority of waste drums, model estimates of VOC concentration within the innermost layer of confinement are equal or greater than the measured VOC concentration. Conservative estimates of the VOC concentration inside a waste drum were calculated assuming a small bag surface area of $500 \mathrm{~cm}^{2}$. This results in higher estimated VOC concentrations but eliminates the problem of determining the minimum bag surface area in each waste drum.

The potential usefulness of this method in characterizing the VOC concentration throughout the entire void volume inside a vented waste drum would be in identifying, with a high degree of certainty, which drums do or do not require additional gas sampling. The method may estimate probable VOC concentrations inside the drum that are so low or so high that additional sampling is unnecessary. By reducing the amount of gas sampling, substantial cost savings and decreased worker exposure to the radioactive waste may be realized. Another potential advantage of the method is the possibility, with the appropriate thermodynamic data, to estimate the VOC content in the waste matrix. This could result in eliminating the need to sample the waste matrix itself.

\section{REFERENCES}

1. Conditional No-Migration Determination for the Department of Energy Waste Isolation Pilot Plant (WIPP), Federal Register, 55(220), 47700, (1990).

2. Safety Analysis Report for the TRUPACT-II Shipping Package, Rev. 12, Nuclear Packaging, Inc., September 1992.

3. G. A Lugg, "Diffusion coefficients of some organic and other vapors in air," Analytical Chemistry, 40, 1073 (1968).

4. R. B. Bird, W. E. Stewart, and E. N. Lightfoot, Transport Phenomena, John Wiley: New York, 1960.

\section{DISCLAIMER}

\footnotetext{
This report was prepared as an account of work sponsored by an agency of the United States Government. Neither the United States Government nor any agency thereof, nor any of their employees, makes any warranty, express or implied, or assumes any legal liability or responsibility for the accuracy, completeness, or usefulness of any information, apparatus, product, or process disclosed, or represents that its use would not infringe privately owned right:. Reference herein to any specific commercial product, process, or service by trade name, trademark, manufacturer, or otherwise does not necessarily constitute or imply its endorsement. recommendation, or favoring by the United States Government or any agency thereof. The views and opinions of authors expressed herein do not necessarily state or reflect those of the United States Government or any agency thereof.
} 


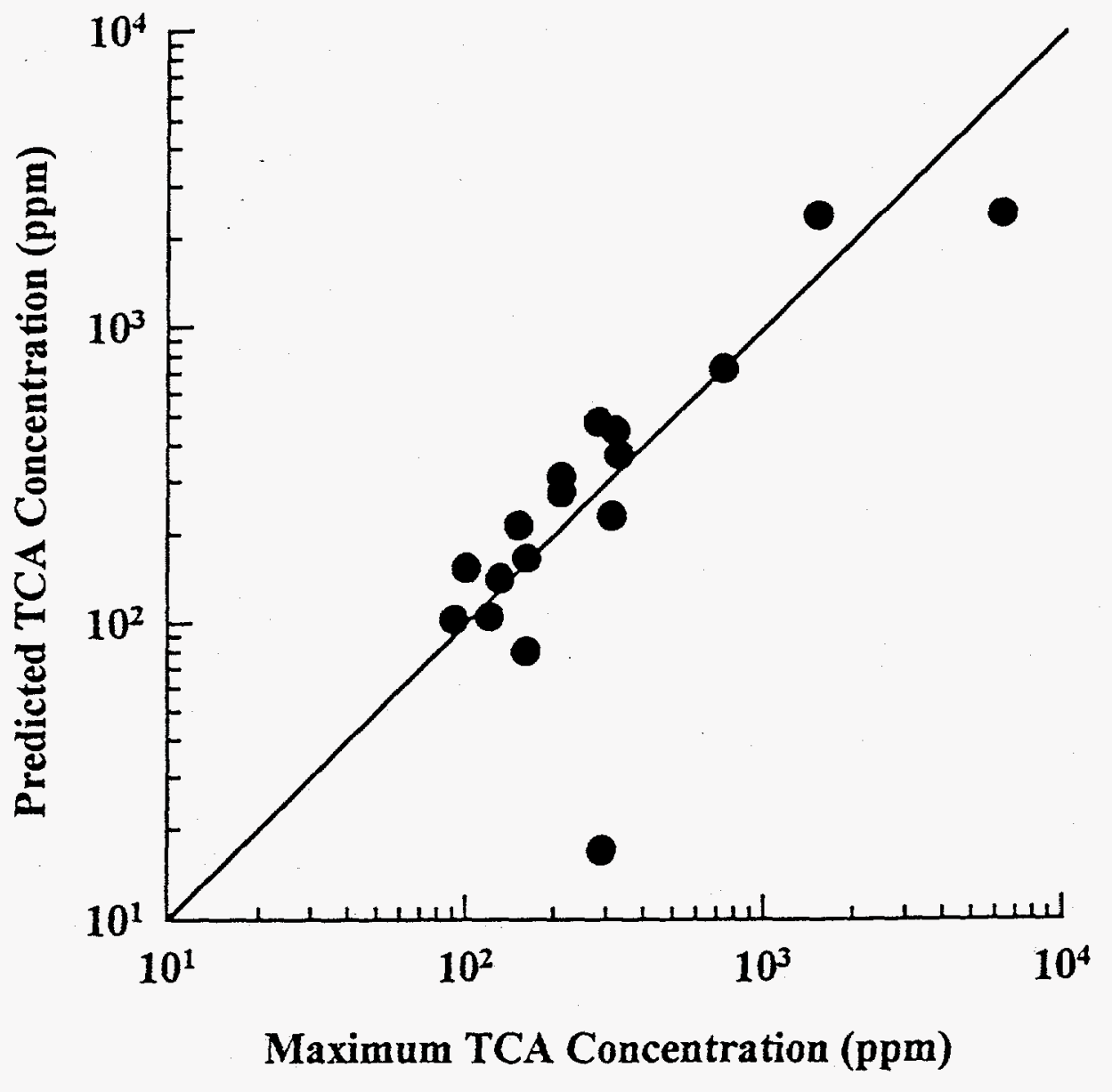

Figure 1. Comparison of predicted and measured TCA concentrations in vented waste drums using smallest estimated permeable surface area for small bags. 


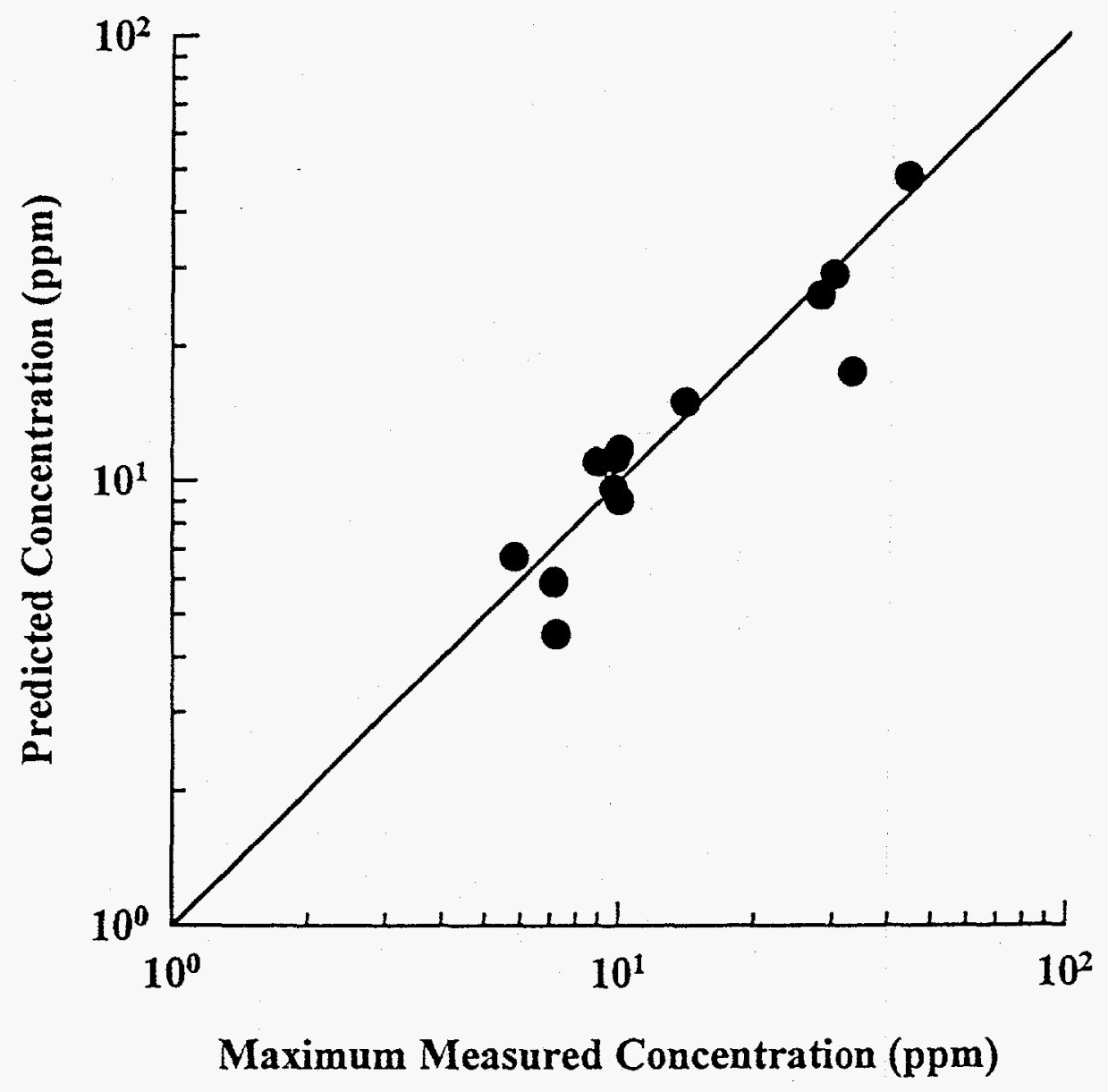

Figure 2. Comparison of predicted and measured toluene concentration in vented waste drums using smallest estimated permeable surface area for small bags. 


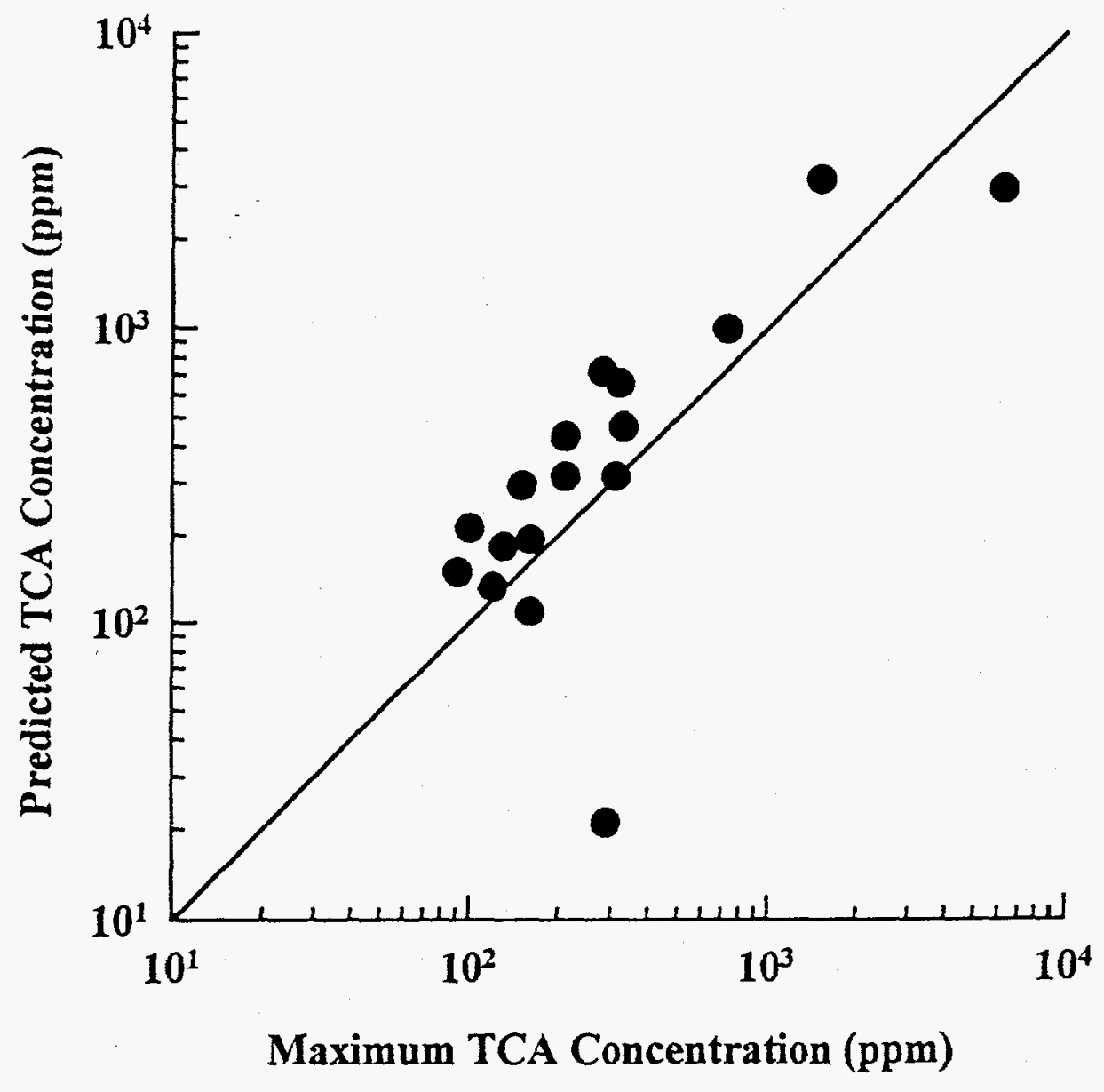

Figure 3. Comparison of predicted and measured TCA concentrations in vented waste drums assuming a small bag permeable surface area of $500 \mathrm{~cm}^{2}$. 


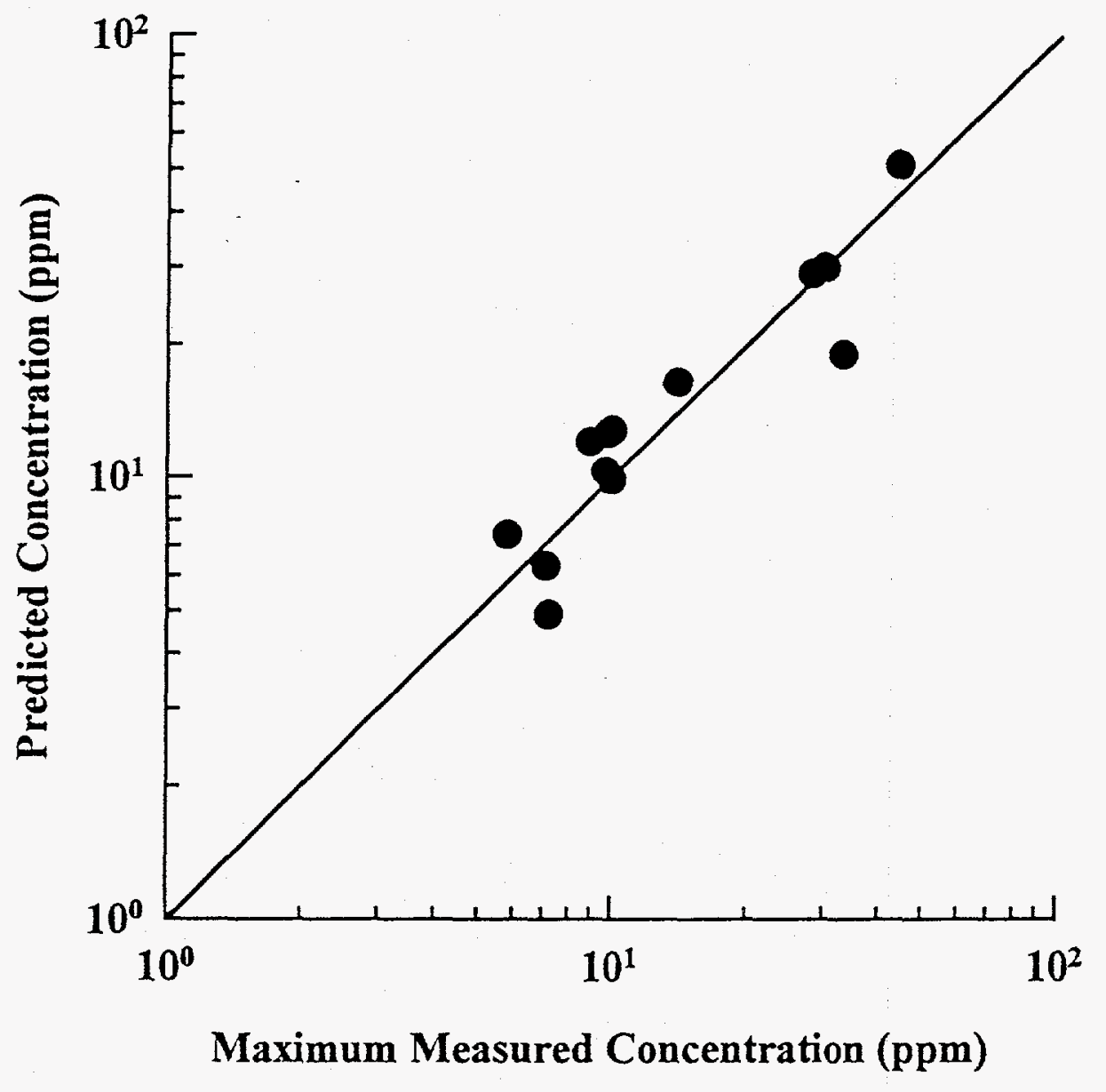

Figure 4. Comparison of predicted and measured toluene concentrations in vented waste drums assuming a small bag permeable surface area of $500 \mathrm{~cm}^{2}$. 